\title{
Are They Using the Data? Teacher Perceptions of, Practices with, and Preparation to Use Assessment Data
}

\author{
Louis S. Nadelson ${ }^{1, *}$, Jennifer Throndsen ${ }^{1}$, J. Eric Campbell ${ }^{1}$, Melanie Arp ${ }^{1}$, Melanie \\ Durfee $^{1}$, Kami Dupree ${ }^{1}$,Tyler Poll ${ }^{1, *} \&$ Sydnie Schoepf ${ }^{1}$ \\ ${ }^{1}$ Emma Eccles Jones College of Education and Human Services, Utah State University, 2805 \\ Old Main Hill Road, Logan, UT 84322, USA. Tel: 1-208-797-7697. E-mail: \\ louisnadelson@gmail.com
}

Received: June 7, 2016 Accepted: June 27, 2016 Published: September 1, 2016

doi:10.5296/ije.v8i3.9567 URL: http://dx.doi.org/10.5296/ije.v8i3.9567

\begin{abstract}
Teacher instructional and curricular choices should be informed by student level assessment data; however, there is a dearth of empirical research documenting teachers' perceptions, uses, and preparation to use assessment data. To address this gap in understanding, we surveyed teachers working in two public school districts in the western United States, resulting in a sample consisting of $52 \mathrm{~K}-12$ teachers. Our results revealed a number of relationships between engaging in professional development, uses of assessment data, and perceptions of the value of the data. We found a number of anticipated relationships, including that teachers who are more comfortable using assessment data in their practice tend to feel less overwhelmed with using assessment data. We also found several paradoxical relationships such as the more teachers engage in professional learning communities the less they create and use common assessments. Our research has a number of important implications for structuring teacher professional development in ways that enhance effective use of assessment data by educators to inform their practice. Our findings also provide a foundation for a deeper examination of teacher perceptions of, uses of, and preparation to use assessment data.
\end{abstract}

Keywords: teacher practice, assessment data, professional development, formative assessment, summative assessment 


\section{Introduction}

As humans, we grow and learn through interactions with our environment including the people and objects we encounter (Lave \& Wenger, 1991; Vygotsky, 1978). According to Dehaene (2011) these interactions influence how we think. From a classroom perspective, teachers use their interactions with students to assess how they learn, grow, and adapt. While there is an abundance of data available for educators to consider in making instructional and curricular decisions, student-learning data may be most relevant and critical to teacher effectiveness (Lalli, Browder, Mace, \& Brown, 1993; Stiggins, 2002, 2005). Having data upon which to base instructional and curricular choices increase teachers' ability to align their practices with the needs and capacity of their students (Stiggins, 2002, 2005). Further, because there is power associated with using data, the capacity to effectively interpret and apply data could be troublesome or beneficial to teachers' status and professional opportunities (Coburn \& Turner, 2011). Thus, there is justification for examining how teachers perceive and use assessment data to guide their practice and professional goals and their preparation to achieve these goals.

To determine the availability of extant research on teacher perceptions and preparation to use assessment data we searched the literature for prior studies. We found studies addressing how teachers integrate classroom assessment with instruction from professional development opportunities (Bergan, Sladeczek, Schwarz, and Smith, 2001; Black, Harrison, Lee, Marshall, \& Wiliam, 2003; Carpenter, Fennema, Peterson, Chiange, \& Loef, 1989). However, we were not able to locate any directly aligned research, suggesting potential gaps in the literature reporting teacher perceptions, use and preparation to apply assessment data to guide their practice. We, therefore, determined a need to gather empirical evidence to address these gaps.

Our research provides a unique contribution to the literature by explicitly examining how teachers perceive and use student data to guide their practice and how teachers perceive the experiences preparing them to effectively use the data. Additionally, our research better informs the field in how to engage teachers in analysis of assessment data, assist teachers in their use of data to increase teaching effectiveness, and examine the relationship between teacher consideration of data and their instructional and curricular decisions. In our experience, teachers are expected to analyze school, district, or state assessment data and make appropriate adjustments to their practice to increase student performance. However, the literature lacks documentation of the ways teachers use different sources of student achievement data to inform their practice and the ways they justify the uses of these data. One goal of our study was to focus more directly on the ways in which teachers use different sources of data to inform their instructional practice. We also sought to gain a deeper understanding of the level to which teachers tend to consider different sources of data to inform their practice.

\section{Conceptual Framework and Review of Literature}

\subsection{Types of Assessment Data}

Assessment data tends to fall within two main categories - summative or formative (Gronlund, 1998). These terms define the frequency of assessments, as well as teachers' intended use of 
the assessment data. Traditionally, summative assessment refers to the assessment of learning, which is typically gathered at the end of the unit of study (Shavelson, Young, Ayala, Brandon, Furtak, et al., 2008); whereas formative assessment is assessment for learning, which is typically gathered during the unit of study (Hoover \& Abrams, 2013; Wiliam, 2007). Common forms or types of summative and formative assessments include: teacher-generated tests, benchmark or interim assessment (Datnaw \& Hubbard, 2015), textbook-generated assessments, department common assessments, portfolios, concept mapping (Brandstädter, Harms, \& Großschedl, 2012), performance assessments, and rubrics (Mui So \& Hoi Lee, 2011). Although summative assessment occurs at the end of the unit (Hoover \& Abrams, 2013; Wiliam, 2007), Black and Wiliam (2003) report that summative assessments may be examined as formative assessments, and if teachers learn to use them as such, they have the potential for using summative assessments to inform their instructional and curricular choices.

Through the use of multiple and varied assessment measures teachers may assess their students' content knowledge before, during, and after instruction. Prior to instruction, teachers may assess their students' levels of understanding through pre-assessments, such as benchmark assessments. Benchmark assessments may be both formative and summative (Good, Kaminski, Smith, Laimon, \& Dill, 2003). Considering benchmark assessments formatively, teachers may use the data to guide instructional planning. During instruction, teachers rely on varying forms of formative assessment data to determine student-learning progress (Heritage, 2007). According to Crooks (1988) after-instruction assessment data serves as feedback for both teachers and students, informing them about the levels of targeted content learning. Thus, teachers can use both summative and formative assessment data to make instructional adjustments that promote student learning (Black \& William, 2003; Herman, Osmundson, Dai, Ringstaff \& Timms, 2015).

The potential variation in teacher use of assessment data based on the nature of the assessment data provides justification for examining teacher perceptions and use of a range of assessment data. Furthermore, the perpetual evolution of the diversity of data accessible to teachers to assess student achievement, suggests an ongoing need to document teachers' assessment data perceptions and practices.

\subsection{Teacher Practice Based on Data}

The conceptual framework of our research is teacher practice and how teachers use assessment data to inform instructional and curricular decisions. The ease and accessibility of modern technology accelerates the collection of student learning data, making such data abundant and relatively easy for teachers to access (Wayman, 2005). However, to leverage the widespread access to a vast array of student level achievement data, educators need the capacity to effectively analyze, interpret, and perhaps respond to the available data (Erwin, 1991). The potential for analysis of educational data to inform educational practice should be of particular interest to teachers who are widely recognized as being primarily responsible for student learning and achievement (Wiggins, 1998). Indeed, proper analysis of student performance data has the potential to greatly influence the quality of education (Crooks, 1988; Doyle, 2003; Lafee, 2002). We contend that for teachers to effectively use student achievement data as an 
instructional and curricular guide requires understanding if, when, and how to use the data to inform classroom practices.

As we previously shared, research suggests teachers gather and use data from multiple forms of assessment to inform their practice (Datnow \& Hubbard, 2015; Hoover \& Abrams, 2013). However, gaps in the literature addressing how teachers indicate using data to inform their instruction remains. The gaps may in part be explained by the perpetual change in teacher access to data, expectations for teacher interpretation and data driven decision making, and research on teachers' use of data from the perspective of the teacher (Datnow \& Hubbard, 2015). Thus, there is justification for on-going examination of the various facets of how teachers access, interpret, and use data to inform their practice.

According to Hoover and Abrams (2013), teachers most commonly report the use of data to differentiate instruction for remediation (96\%), re-teach concepts (94\%), and to change the pace of instruction (92\%). In contrast, Hoover and Abrams also report that only about $30 \%$ of teachers are likely to re-teach concepts as the remaining $64 \%$ of the responding teachers reported that re-teaching was not possible due to concerns for maintaining expected curricular pacing. We maintain that the misalignment between the large percentage of teachers who report using data to inform decisions to re-teach concepts and the actual percentage engaging in re-teaching illustrates potential differences between teacher perceptions of possible uses of data and actual modifications teachers make to their practice based on data. Thus, there is warrant for examining and gaining deeper knowledge of how teachers perceive they are using data and their preparation to use the data to better understand the disparities between teacher perceptions of their use of data and their actual use of data.

Datnow and Hubbard (2015) contend that despite teachers' perceiving that the use of student achievement data is important to guide their practice decisions, many teachers view the requirement to formally examine the data as a "bureaucratic task to be completed" (p. 9). Teacher perceptions of examining student data as a hoop to jump through suggests that teacher use of data may be constrained due to perceptions of the sources as motivation rather than the perceived value of the information for guiding their instructional practice. The potential association between teacher perceptions of why they are required to examine data and the potential for data to guide teacher practice provided merit for our investigation of teachers' perceptions of the use of assessment data and their preparation to use the data.

\subsection{Acquiring Assessment Data}

The amount of student learning data available to educators is abundant (Hamilton, Halverson, Jackson, Mandinach, Supovitz, et al., 2009). The push for collecting abundant student achievement data is a result of recent research, which has shown that gathering, analyzing, and responding to student learning data during instruction can increase opportunities for teachers to increase student-learning achievement (Hattie, 2009). The increases in student learning data acquisition and expectations that teachers make databased instructional and curricular decisions have become increasingly common with the expanded accountability policies associated with student academic performance (Bancroft, 2010). Thus, due to educational 
policymakers' desire to document teacher effectiveness, the use of assessments and application of data for accountability are at an all-time high.

Essential to decision making in education is student-achievement data (Hojnoski, Gischlar, \& Missall, 2009). As shared previously, learning assessments can be typically categorized as either formative or summative (Harlen \& James, 1997). Educators, school district administrators, policymakers, and the general public most commonly rely on summative, high-stakes tests to gather student achievement data by means of state level assessments to determine teacher and school effectiveness (Milanowski, 2004). Teachers may use annual state assessments as a source of information to make instructional decisions; however, the assessments tend to be administered once at the end of each school year limiting their usefulness in terms of student progress and teacher effectiveness (Young \& Kim, 2010). Another common approach for gathering summative data is through interim-district adopted assessments, which are administered periodically to assess achievement at the classroom, grade, school, or district level (Hamilton et al., 2009). Alternatively, teachers tend to rely on end-of-unit summative assessment data to determine student course progress (Shepard, 2000).

In contrast, formative assessment data is commonly gathered by teachers both formally and informally to monitor their students' understanding of what is being taught and adjust instruction and curriculum emphasis with the goal of increasing student learning (Cornelius, 2013). Teachers may rely on a number of educational tools and technology to gather and analyze formative assessment data to identify students who are meeting learning proficiency and students who may be in need of remediation (Dunn \& Mulvenon, 2009). The importance of assessment data to teacher practices provides justification for examining how teachers perceive assessment data and their preparation to use the data.

The most common reasons for the administration of assessments is to collect data, help guide instructional planning, evaluate the curriculum, and determine students' progress on learning goals (Shapiro et al., 2012). Assessment data provides a basis for evidence-based monitoring of student learning progress and may help guide students and teachers as they strive to achieve learning goals (Brookhart, 2007). Teacher understanding of when and how to use the array of assessment data available to inform their practice provides support for examining teacher preparation to use assessment data, their perceptions of assessment data, and their interactions with the data.

\subsection{Teacher Practice and Assessment}

A substantial gap in the literature exists with regards to teacher practice of assessment and the professional development opportunities that have encouraged the use of different assessment tools available to educators. Since 1976, a number of studies published focused on in-service and professional development opportunities related to assessment data, though "relatively few of these studies have focused on the effects of in-service education and training on teachers, schools or children" (Halpin, Croll \& Redman, 1990, pg. 163). While the extant research identifies professional development opportunities related to the use of assessment data, there remains a gap in the research in relation to how many teachers change their practices to implement new practices based on data-driven decision-making. Thus, Parise and Spillane 
(2010) report, "the extent to which teachers' learning opportunities facilitate change in their classroom practice remains unclear” (p. 324).

Even less evidence exists related to teacher use of assessment data. The research regarding use of assessment data in general is a rather new focus of study; however, research suggests that even when teachers "... use a series of assessments during the course of instruction, they tend to be short-term ways of obtaining summative information for the purposes of assigning grades rather than the formative information for the improvement of teaching and learning" (Black \& Wiliam, 1998 as referenced in Feldman \& Capobianco, 2008, p. 83). Black and Wiliam's (1998) meta-analysis did identify "surprisingly large effect sizes for well-developed formative assessment practices" (Black \& Wiliam, 1998 as referenced in Sato, Wei, \& Darling-Hammond, 2008, p. 670). Many questions remain regarding how teachers decide on the assessments they utilize to determine the efficacy of their assessment, and the utilization of assessment data to guide their instruction. The research, as of yet, has no definitive answers. There remains increasing concern from many educational stakeholders regarding the effectiveness of professional development, especially its direct correlation to student achievement outcomes (Penuel, Fishman, Yamaguch, \& Gallagher, 2007). An examination of the availability and use of assessment data for the benefit of student achievement by teachers in relation to teacher engagement in professional development has yet to be examined. Most of the current research focuses on determining the length of time teachers should be engaged in professional development activities in order to achieve optimum outcomes (Kinnucan-Welsch, Rosemary, \& Grogan, 2006) and not how they are using what they learn in their professional development experiences to guide their practice. Our research addressed this gap in the literature by examining the link between professional development of teachers focused on the use of assessment data and their actual use of assessment data.

\subsection{Using Assessments - Best Practices}

We argue that teachers' best use of student achievement data to guide curricular and instructional decisions requires balancing two practices. First, teachers need ongoing support for interpreting and using data. Second, teachers need opportunities to choose what types of assessments to use for their formative needs, which means teachers need opportunities for autonomy in gathering and interpreting data in their classrooms. We argue that these two practices, when balanced, provide the highest potential for gains in student achievement. Thus, there is justification for examining teachers' preparation to use assessment data to inform their practice and their preference of student assessments to gather the desired data to inform their practice.

Teachers' most effective use of student achievement data happens when the data they access is gathered as part of a school-wide comprehensive effort (Italiano, 2014). Educators use student achievement data more productively when the classroom data they gather is part of a school system of data, and that school system of data is part of a larger system of data (Horn, Kane \& Wilson, 2015). In addition, teacher evaluation of assessment data in the context of professional learning groups tends to be more effective for guiding their practice, as opposed to individual teachers evaluating data on their own (Bernhardt, 2000). Further, Bernhardt (2002) suggests 
that four types of data, when combined, will provide an accurate account of the collective achievement of expected outcomes: a) longitudinal student learning data, b) demographic data, c) perceptions data, and d) school process data. Longitudinal student learning data provides information regarding differences in student achievement over several years. Demographic data can predict enrollment trends, which helps in budget forecasting. Perceptions data helps record how the perspectives of parents, students, and teachers relate to teaching and learning which is important to monitor, as perceptions tend to evolve over time. School-process data allows educators to use evidence-based analysis to define effective or ineffective school programs, instructional strategies, as well as teacher classroom practices. School process data can also provide educators with the evidence necessary to guide their understanding of significant influences on student achievement. When combined, teachers may be able to use these four facets of student data to effectively inform decisions of practices and curricular choices (Bernhardt, 2000).

Policy alone should not direct how teachers use data to decide what instructional practices and curricular choices will result in optimal levels of student learning (Italiano \& Hine, 2014). As recommended by Horn et al. (2015), we maintain that communication affords an opportunity for teachers to provide feedback to policymakers about data acquisition processes. We argue that teachers may have very different perceptions than policymakers with regard to the types of assessment data that are useful for guiding their practice and optimizing student learning. Thus, we argue that the potential rift between policymakers' and teachers' perceptions of useful assessment data provides justification for investigating what assessment data teachers rely on to guide their practice and how useful they perceive the array of data to which they have access for informing their professional decisions.

\section{Guiding Research Questions}

We designed our research to address the gap in the literature we presented in our introduction and review of literature regarding empirical evidence of teacher uses, practices, preparation, and perceptions associated with assessment data. Our overarching purpose for this research was to determine how teachers perceive and use the array of assessment data available to them and their professional preparation to effectively use the data. To guide our research on K-12 teachers' knowledge, preparation, perceptions, and uses of assessment data, we developed the following questions to guide our investigation:

\section{How do teachers use assessment data?}

2. What are teachers' professional development experiences and practices associated with use of assessment data?

3. What is the level of teacher knowledge and comfort for the effective use of assessment data?

4. What resources, processes, and tools are teachers using to evaluate assessments and outcomes?

5. How do teachers perceive the assessment tools and resources in terms of usefulness and effectiveness? 


\section{Ml Macrothink}

6. How often, for what reasons, and with whom are teachers analyzing and interpreting data?

\section{Methods}

\subsection{Setting and Data Collection}

For our research we surveyed teachers from two local education authorities (LEAs) using an on-line survey. Both LEAs were located in the intermountain western United States. One LEA was a charter school located in a suburban neighborhood. The other LEA was a school district located in a rural community.

All data collection was anonymous and voluntary. We emailed the teachers in the two LEAs inviting them to participate in our research, providing the teachers with information about our research goals and a link to our survey. We also received support from the principals in the schools who encouraged teachers to participate in completing the survey. To allow the teachers sufficient time to complete the survey we provided them with open access to the survey for two-weeks following the initial distribution of the email invitation. After the two weeks of data collection we closed the survey.

\subsection{Participants}

The participants in our study were a convenience sample of teachers from two LEAs in the western United States. Seventy-two participants started the survey with about $72 \%(n=52)$ fully completing the survey. Of those 52 participants, $36(69 \%)$ were female and $16(31 \%)$ were male with a mean age of $44.71(S D=12.17)$. Thirty-three of the participants were secondary education teachers while 19 taught at the elementary school level. About $58 \%$ of participants held an advanced degree (29 masters and 1 doctorate) while the balance of the participants held a bachelor's degree.

\subsection{Measures}

\subsubsection{Demographics}

To assess the demographics of our participants we modified an instrument that has been used in prior research. The instrument contained a combination of selected and free response items designed to collect an array of personal and professional characteristics.

\subsubsection{Survey of Teacher Perceptions and Interactions Assessment Data}

Unable to locate an extant instrument aligned with our research goals, we created an instrument that effectively assessed K-12 teachers' perceptions, preparation, and use of assessment data. We began our instrument development by identifying areas of significant interest in our investigation and in alignment with our research questions as well as our review of the literature. In alignment with our literature supported research questions, we specifically sought to gather data addressing teacher uses, practices, professional development, value, and beliefs associated with assessment process and assessment data. 
As a team, we constructed several items for each of our targeted areas of interest. Once we had a compiled a working version of the survey, we took turns examining and considering each of the items for relevancy and redundancy. Given the unique and exploratory nature of our research, we determined that establishing the validity of our measure was suitably handled among the seven of us on the research team.

Our final instrument contained a collection of selected response Likert scale items to assess perceptions of interactions with assessment data, and similar selected response items for assessing other aspects of uses and trust in assessment data. The selected response items included stems such as, "I use assessment data results to adjust my instruction" and "I use assessment data results to compare my performance to that of other teachers" which participants were asked to responded to using a five-point scale ranging from "Never" (1) to "Very Frequently" (5). We also included a series of items such as "How helpful are state generated assessments in helping you guide classroom instruction" and "How helpful are computer-based assessments in helping you guide classroom instruction" to which the participants responded on a five-point scale ranging from "Unhelpful" (1) to "Extremely Helpful" (5). The final set of items we included in the survey asked the participants to respond to items such as, "How often do you meet with other teachers at your school to discuss state assessment data" on a five point scale ranging from "Never" (1) to "All The Time" (5). The reliability analysis of our instrument selected response items produced a Cronbach's alpha of .73, which indicates an acceptable level of reliability.

\subsection{Analysis}

To analyze the outcome of our survey we considered the responses to the survey items individually by research question and by construct. We also analyzed the results in terms of positive and negative responses and the associated correlations. Further, we examined the participants' responses both descriptively and inferentially, calculating averages and examining the relationships among items.

\section{Results}

\subsection{Using Assessments}

Our first research question asked, How do teachers use assessments? To answer this question, we examined the responses to our survey items that asked participants to indicate how they used assessment data to inform their instruction. Our related survey items focused on instructional adjustments, student needs, as well as teacher use of formative and summative assessment. The results of our analysis (see Table 1) indicate that teachers most often rely on formative assessment data to inform their classroom practices $(M=4.09 ; S D=.83)$. In contrast, teachers tended to be least reliant on state summative assessment data to inform their practice $(M=2.85 ; S D=1.09)$. 
Table 1. Levels of Teacher Use of Different Assessment Data to Inform Their Practice

\begin{tabular}{lc}
\hline Uses of Assessment & Mean (SD) \\
\hline Formative assessment data to inform my classroom practices & $4.06(.83)$ \\
Determine the learning needs of individual students & $3.94(.96)$ \\
Adjust my instruction & $3.90 \quad(.82)$ \\
Identify student skill level deficiencies & $3.88(1.06)$ \\
To monitor student progress & $3.87(.91)$ \\
Student grading & $3.33(1.22)$ \\
To group students for learning activities & $3.19(1.27)$ \\
Compare the performance to that of other teachers & $2.94 \quad(1.39)$ \\
State assessment data to inform instruction & $2.85(1.09)$ \\
\hline
\end{tabular}

\subsection{Professional Development and Assessment}

Our second research question asked, What are teachers' professional development experiences and practices associated with their use of assessment data? To answer this question, we asked participants to approximate the number of professional development hours within and outside their district they had engaged in during the past year. Additionally, we asked the participants to indicate the portion of those professional development hours dedicated to increasing their understanding of the use of assessment data.

Our analysis revealed that the mean number of professional development hours spent within the district was about 21.5 hours $(S D=8.91)$, while outside of the district professional development was an average of about 17 hours $(S D=23.18)$. Of the time engaged in professional development, an average of about 8.4 hours $(S D=10.43)$ or about $40 \%$ of the district level professional development time was focused on using assessment data to guide teacher practice and just under 3 hours $(M=2.78 ; S D=6.23)$ or about $16 \%$ of outside the district professional development time was related to using assessment data to inform professional decisions.

To determine if our participants perceived the professional development focused on using assessment data for teaching to be of high quality and effective, we examined the responses to several related three-point Likert scale like items. We conducted a series of t-tests using " 3 " as the comparison value which was coded to "strongly agree." We found that on average, teachers did not perceive the assessment-focused professional development in which they engaged to be of high quality $(M=1.71, S D=.67, t=13.93, p<.01)$. Our result suggests that the participants likely perceived the professional development they engaged in to be of low quality in terms of meeting their learning needs associated with using assessment data to guide their practice.

We continued our analysis by examining the responses to a three-point Likert scale item used to assess the participants' perceptions of their preparation to effectively use formative assessment data and a five-point Likert scale item assessing participants' level of seeking professional development to increase their ability to effectively use assessment data. We found that teachers did not feel adequately prepared to effectively use formative assessment data $(M=$ 
$1.50, S D=.73, t=14.87, p<.01)$, but only moderately engaged in seeking professional development to be more effective $(M=3.15, S D=1.11)$. Our results suggest that the participating teachers do not feel they have been adequately prepared to effectively use formative assessment data, but are only moderately engaged in seeking professional development opportunities to increase their effectiveness.

We did find an interesting positive correlation between teachers feeling overwhelmed by professional development experiences and their perception of professional development being high quality $(r=.32 ; p<.05)$. Interpreted, our results suggest that when teachers perceive they have received high quality professional development they tend to be overwhelmed with using assessment data, or conversely, when the professional development quality is low, the participants tend not to be overwhelmed with using assessment data.

\subsection{Knowledge and Comfort Using Assessment Data}

Our third research question asked, What is the level of teacher knowledge of and comfort for the effective use of assessment data? To answer this question, we examined the items in our survey that asked respondents to share their level of knowledge of assessment data, as well as their comfort analyzing and interpreting assessment data for instructional use. We found a negative correlation between participants' knowledge of the range of assessment data available to them and their feelings of being overwhelmed $(r=-.30 ; p<.05)$. Interpreted, our analysis suggests as teachers' knowledge of assessments increases, feelings of being overwhelmed by assessment focused professional development tends to decrease. Similarly, when participants indicated that they were confident in their understanding of interpretation of data, they felt less overwhelmed with the assessment-related professional development experiences $(r=-.29 ; p$ $<.05)$.

One of our more interesting findings was an inverse relationship between the participants' perceptions of being adequately prepared to use common formative assessments and the perceptions of state level assessments as a waste of time $(r=-.34, p<.05)$. Our results indicate that as participant preparation to use formative assessment data increases, their perceptions of state level assessments of student learning as a waste of time decreases.

Another inverse relationship we found was between a participants' struggle to understand assessment data and the levels of discouragement when they are performing lower than their peers $(r=-.29, p<.05)$. Interpreted, our data suggests that as teachers' levels of struggle to understand assessment data increases, their levels of discouragement of performing lower than their peers' decreases. Alternatively, as discouragement for performing lower than peers increases the struggle to understand assessment data decreases.

\subsection{Evaluating Assessment Data}

Our fourth research question asked, What resources, processes, and tools are teachers using to evaluate assessments and outcomes? To answer this question, we examined the responses to our survey items that focused on teacher use of resources or tools to evaluate assessment and student learning outcomes. We began our analysis by examining what resources the participants would reference for information about the use of assessment data to further 
educate themselves and inform their teaching. Our analysis revealed that the participants had highest consideration for building principals (28), district personnel (28), and the internet (25). The lowest levels of consideration by the participants were journals (11) and colleges of education (12) (See Figure 1).

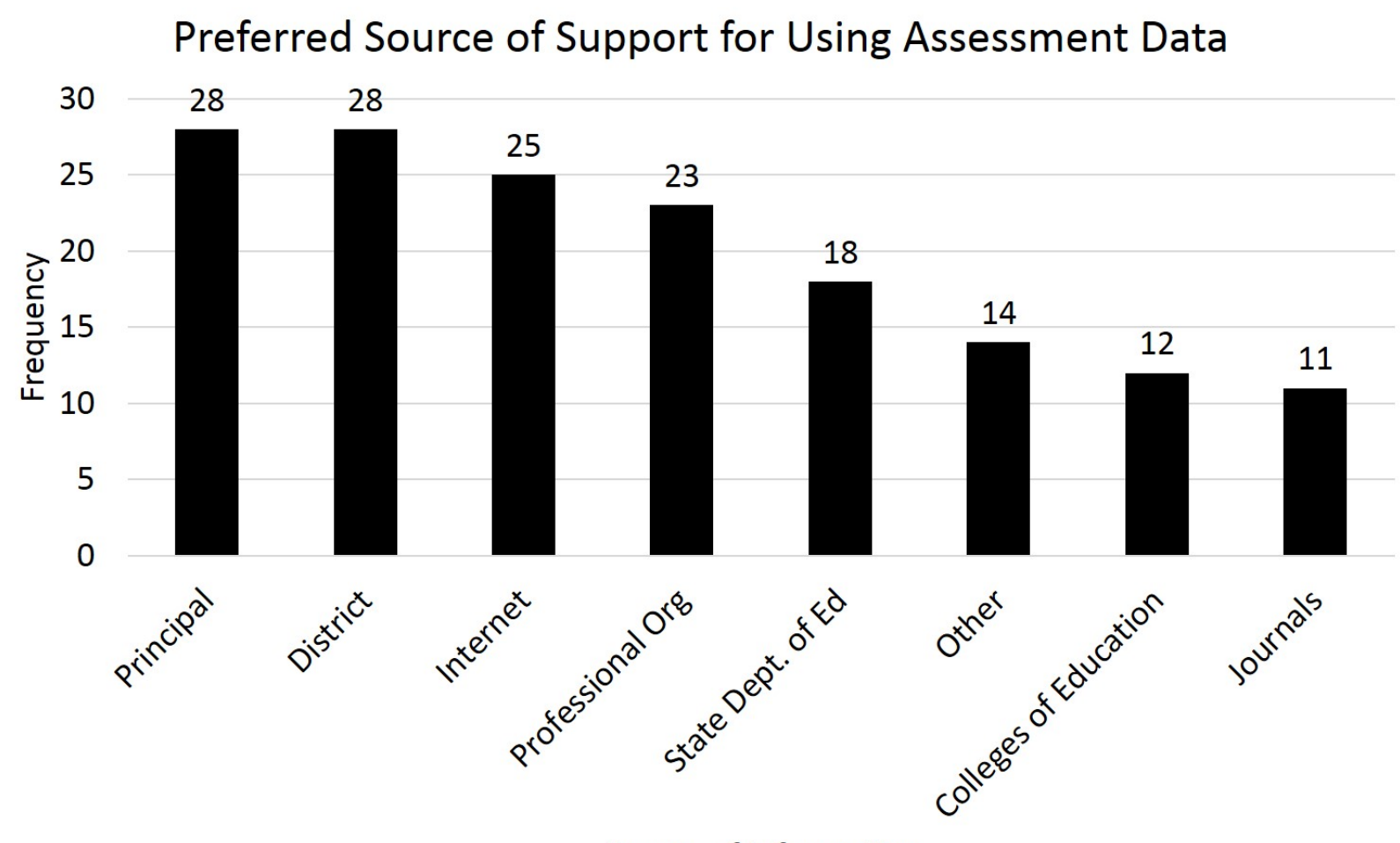

Source of Information

Figure 1. The Resources Teachers Would Reference for Support in Using Assessment Data to Inform Their Instruction.

As we continued our analysis of process and resources, we examined the relationship between the participants' frequency in engaging in analyzing student assessment data within a professional learning community and the frequency in which they were part of a team involved in creating common summative and formative assessments $(r=-.41 ; p<.01)$. The outcome suggests a paradoxical relationship such that as teachers engage more in professional learning communities their engagement in teams to create and use common formative and summative assessments decreases.

Similarly, we also found an inverse relationship between the frequency with which teachers meet to discuss state assessment data and the adequacy of preparation to effectively use formative assessments. $(r=-.35 ; p<.05)$. Interpreted, the relationship suggests that as teachers engage more in meetings to discuss state level assessment data, their perception of preparation to effectively use formative assessments decreases. 


\subsection{Usefulness of Assessments}

Our fifth research question asked, How do teachers perceive the assessment tools and resources in terms of usefulness and effectiveness? To answer this question, we examined our survey items related to the participants' perceptions of assessments being useful and effective tools. In our examination of the participants' use of state level assessments, we found a positive correlation between the participants' perceptions of these assessments being a waste of time and the engagement in using the state level assessments to inform instruction $(r=.33, p<.05)$. Interpreted, the correlation suggests a paradoxical relationship indicating that as perceptions of state level assessments being a waste of time increases so does the level of engagement in using the assessments to inform instruction. We also found a positive correlation between the participants' engagement in using state level assessment data to inform their instruction and their referencing of year-end assessment data to determine areas of instructional focus for the upcoming year $(r=.49, p<.01)$. Interpreted, these data suggest that as engagement in using state level assessments increases, referring to year-end assessment data to guide future practice also increases.

Through our analysis we found inverse correlations between teachers' perceptions of classroom-based assessments as being helpful for guiding their instruction and their use of end of year assessments to guide their future practice $(r=-.33, p<.05)$, which suggests that as teachers find classroom-based assessments more useful, they find end of year assessment less useful for guiding practice. We did find a positive relationship between classroom-based assessments and use of formative assessments $(r=.30, p<.05)$, which suggests as teachers find classroom assessment more useful; they also find formative assessments more useful.

\subsection{Frequency of Assessment Use}

Our final research question asked, How often, for what reasons, and with whom are teachers analyzing and interpreting data? In order to answer our research question, we examined the several survey items, which measured teachers' reasons for analyzing and interpreting assessment data. Our analysis yielded that formative assessment data to inform classroom practice $(M=4.06, S D=.83$ on a scale of 5$)$ was the top reason teachers engaged in analyzing and interpreting data (see Figure 2). Closely following was using assessment data to determine student learning needs $(M=3.94, S D=.96)$, skill deficits $(M=3.88, S D=1.06)$, and as a vehicle for adjusting instruction $(M=3.9, S D=.82)$. However, the teachers indicated that year-end or state level assessment data were not useful empirical references for adjusting their instruction $(M=2.85, S D=1.09)$ or lesson plans $(M=2.83, S D=.99)$. 


\section{Mean Frequency of Use of Assessments}

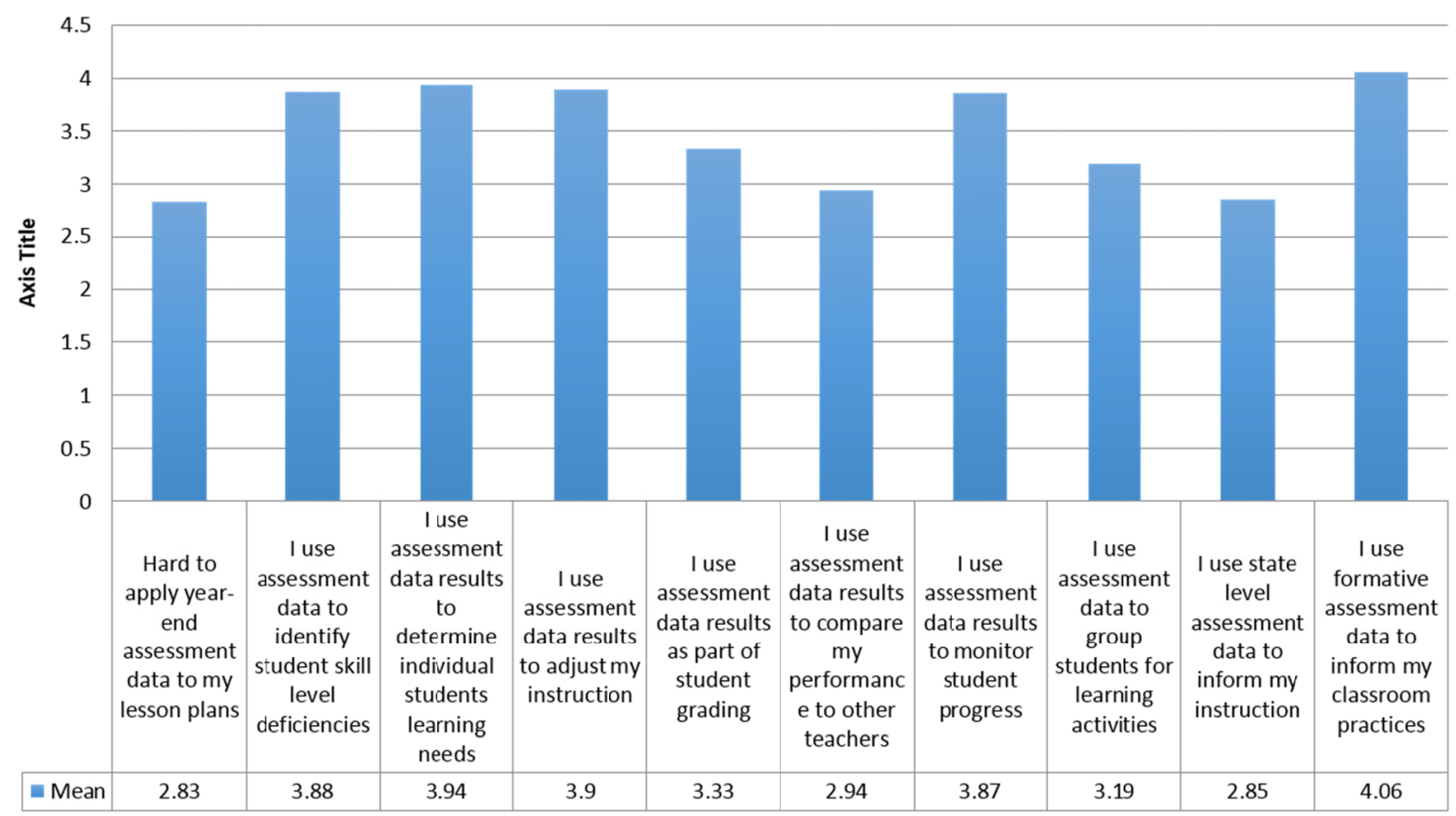

Figure 2. Frequency of teachers' use of different forms of assessment data (based on a 5-point Likert scale)

\section{Discussion and Implications}

Given the abundance of assessment data in K-12 education and the expectation for teachers to make data-driven decisions, there is justification for examining how K-12 teachers perceive, use, and prepare to effectively use the assessment data. Yet, a gap exists in the literature empirically documenting teachers' thoughts about and engagement with assessment data. Our research was a step in filling the gap as we empirically documented a range of teachers' perceptions and interaction with a variety of student learning assessment data.

In our examination of teacher uses of assessment data, we found that teachers tend to rely more on classroom level formative assessment than summative assessments, such as state level competency tests or district level end of year exams. We found multiple significant correlations and other data evidence that reinforces aspects of this finding. We speculate that teachers continually gather data as they teach using formative assessments, which they rely heavily upon to guide their instructional and curricular choices. The nearly constant stream of formative assessment data is essential feedback for teachers as they reflect on their effectiveness and progress of their students' learning. In contrast, the annual evaluation data comes at the end of the year after most teachers have completed their work with students, and therefore the assessment data cannot be used to make any immediate adjustments to practice, as the practice has essentially been completed. While the data may be used to inform future practice, their future students may have different capabilities and knowledge that may not align 
with the capacities of the prior students from which the summative assessment data was drawn, making formative assessment much more meaningful for guiding practice than an annual summative assessment. The alignment between teacher practice and formative assessment processes and data explains the greater levels of teacher preference, comfort, and frequency of use of formative assessment data compared to other forms of assessment, particularly data from large scale annual summative assessments.

Our investigation of teacher engagement in, perceptions of, and preparation by student learning assessments-focused professional development reflects a need to spend more time and thought in designing the content and delivery of the professional development. For the most part, teachers did not find assessment focused professional development to be of high quality or useful, which suggests that the related professional development was not aligned with the needs of teachers. Given that $40 \%$ of district level professional development time was focused on the use of student learning assessment data, this result is discouraging as it indicates that teachers are largely dissatisfied with the quality of a major portion of their professional development opportunities related to assessment data.

We were intrigued by some of the inverse relationships between the participants' perceptions of their levels of preparation to use data and their perceptions of the value of state level assessments. We posit that as teachers become more prepared to use assessment data, they become more aware of the range of assessment data available for their use, and therefore value these other forms of data at greater levels than state level assessments. Those with limited preparation may not be aware of the range of assessment data available. Yet, given the prominence of state level exams, those with limited preparation are likely to have working knowledge of state level exams of student learning and therefore have determined ways to make the associated assessment data useful for guiding their practice. An important direction for future research is gaining a deeper understanding of the influences and explanations for teachers' perceptions and use of state level assessments.

We found that teachers tend to rely most on their principals and districts and least on colleges of education and professional journals as sources of information on the uses of student assessment data. We suspect that teachers perceive principals and district level personnel as being more aware of the resources available and the needs of the teachers, while faculty in colleges of education and journals are more likely to be out of touch with the conditions of teachers' practice and therefore less likely to provide support aligned with teachers' needs. Given the reliance of teachers on district personnel and principals, it is essential that these individuals have the knowledge of assessment and teacher practice necessary to guide and support their teachers. Ensuring that district and building leaders are also provided with professional development opportunities designed to build their capacity to support teacher assessment data collection, interpretation, and use is critical, so they are prepared to serve as a resource for teachers.

Despite the fact that many professional teacher organizations circulate journals supporting teachers' practice and assessment data use and many colleges of education faculty members are potentially experts on classroom practice and the use of assessment data, these resources were 
recorded as the lowest considered for support by the participating teachers. We speculate that these potential resources do not fulfill the help being sought and immediacy of teacher needs. We were left wondering if the low access to journals and colleges of education for support was due to a perceived inability to relate to the teachers, or if it is difficult for teachers to find the information or expert they are seeking without a time consuming search. Answering these questions could potentially be fruitful directions for future research.

We failed to find a relationship between engaging in assessment-focused professional development and perceptions of the usefulness or value of state level or formative assessments. We speculate that the professional development does not typically influence teachers' perceptions of assessment usefulness, or the perceptions of usefulness are rather static, and therefore, additional professional development has little impact, or the professional development is not effectively designed to enhance perceptions of assessment usefulness. Regardless, there is merit in considering the design of professional development to assure it is meeting the needs of teachers. Exploring the relationship between professional development and teacher perceptions of assessment usefulness is a needed area of additional research.

\section{Limitations}

Our first limitation was the size of the study sample, which may have limited the representativeness of the data to a larger population of teachers' perceptions and experiences. However, we exposed some perceptions and relationships not previously documented in the literature. Thus, while our sample size would not be considered large, the new findings do suggest we found new understanding of teacher perceptions of, practices with, and preparation to use assessment data.

The second limitation of our study was also related to the sample which was drawn for teachers in a single state; however, the participating teachers were from a diversity of schools within the state. Again, the exposure of new empirical evidence of teacher perceptions and practices associated with assessment data makes it difficult to determine if participants from other states would respond differently. In addition, the greater consistency between systems in various state boundaries due to the No Child Left Behind initiative suggests teachers are likely to have similar perceptions and interactions with assessment data in states other than the one in which our participants worked.

The third limitation of our research was that not all K-12 teachers we surveyed were expected to use or even have access to state level assessment data. While all teachers are likely aware of state level assessments, their experiences with and expectation for interacting with state level assessment data may vary due to grade levels and subjects taught. A deeper examination of the relationship between knowledge of and experience with examining state level assessment data is potentially a critical direction for future research. 


\section{Conclusions}

We set out to gain a deeper understanding of teacher perceptions, practices, and preparation to use assessment data. Our survey of a sample of K-12 teachers revealed a diversity of new relationships, interactions with, and applications of assessment data that has not been documented before. Gaining a deeper understanding of how teachers perceive and apply assessment data to their practice can be critical to enhancing their effectiveness of being data driven in their instructional and curricular decisions. There is more work needed to gain a deeper understanding of teachers' uses of student learning assessment data, but our research took a step in filling the gap in the literature.

\section{References}

Bancroft, K. (2010). Implementing the mandate: the limitations of benchmark tests. Educational Assessment, Evaluation and Accountability, 22(1), 53-72. http://dx.doi.org/10.1007/s11092-010-9091-1

Bergan, J. R., Sladeczek, I. E., Schwartz, R. D., \& Smith, A. N. (1991). Effects of a measurement and planning system on kindergarteners' cognitive development and educational programming. American Educational Research Journal, 28(3), 683-714. http://dx.doi.org/10.3102/00028312028003683

Bernhardt, V. L. (2000). Intersections: New routes open when one type of data crosses another. Journal of Staff Development, 21(1), 33-36.

Black, P. J., \& Wiliam, D. (1998). Inside the black box: Raising standards through classroom assessment. Phi Delta Kappan, 80(2), 139-148.

Black, P. J., \& Wiliam, D. (2003). 'In praise of educational research': Formative assessment. British Educational Research Journal, 29(5), 623-637. http://dx.doi.org/10.1080/0141192032000133721

Black, P., Harrison, C., Lee, C., Marshall, B., \& Wiliam, D. (2003). Assessment for learning: Putting it into practice. Buckingham, UK: Open University Press.

Brandstädter, K., Harms, U., \& Großschedl, J. (2012). Assessing system thinking through different concept-mapping practices. International Journal of Science Education, 34(14), 2147-2170. http://dx.doi.org/10.1080/09500693.2012.716549

Brookhart, S. M. (2007). Expanding views about formative classroom assessment: A review of the literature. Formative Classroom Assessment: Theory into Practice, 43-62.

Carpenter, T. P., Fennema, E., Peterson, P. L., Chiange, C. P., \& Loef, M. (1989). Using knowledge of children's mathematics thinking in classroom teaching: An experimental study. American Educational Research Journal, 26(4), 499-531. http://dx.doi.org/10.3102/00028312026004499

Coburn, C. E., \& Turner, E. O. (2011). Research on data use: A framework and analysis. 
Measurement: Interdisciplinary Research \& Perspective, 9(4), 173-206. http://dx.doi.org/10.1080/15366367.2011.626729

Cornelius, K. E. (2013). Formative assessment made easy: Templates for collecting daily data in inclusive classrooms. Teaching Exceptional Children, 45(5), 14-21. http://dx.doi.org/10.1177/004005991304500502

Crooks, T. J. (1988). The impact of classroom evaluation practices on students. Review of Educational Research, 58(4), 438-481. http://dx.doi.org/10.3102/00346543058004438

Datnow, A., \& Hubbard, L. (2015). Teachers' use of assessment data to inform instruction: Lessons from the past and prospects for the future. Teachers College Record, 117(4).

Dehaene, S. (2011). The number sense: How the mind creates mathematics. New York: Oxford University Press.

Doyle, D. P. (2003). Data-driven decision-making: Is it the mantra of the month or does it have staying power? THE Journal (Technological Horizons in Education), 30(10), S19.

Dunn, K. E., \& Mulvenon, S. W. (2009). A critical review of research on formative assessment: The limited scientific evidence of the impact of formative assessment in education. Practical Assessment, Research \& Evaluation, 14(7), 1-11.

Erwin, T. D. (1991). Assessing student learning and development. San Francisco: Jossey-Bass.

Feldman, A., \& Capobianco, B. M. (2008). Teacher learning of technology enhanced formative assessment. Journal of Science Education and Technology, 17(1), 82-99. http://dx.doi.org/10.1007/s10956-007-9084-0

Good, R. H., Kaminski, R. A., Smith, S., Laimon, D., \& Dill, S. (2003). Dynamic indicators of basic early literacy skills. Longmont, CO: Sopris West Educational Services.

Gronlund, N. E. (1998). Assessment of student achievement. Needham Heights, MA: Allyn \& Bacon Publishing.

Halpin, D., Croll, P., \& Redman, K. (1990). Teachers' perceptions of the effects of in-service education. British Educational Research Journal, 16(2), 163-177. http://dx.doi.org/10.1080/0141192900160205

Hamilton, L., Halverson, R., Jackson, S. S., Mandinach, E., Supovitz, J. A., \& Wayman, J. C. (2009). Using student achievement data to support instructional decision-making. IES Practice Guide. NCEE 2009-4067. National Center for Education Evaluation and Regional Assistance.

Harlen, W., \& James, M. (1997). Assessment and learning: differences and relationships between formative and summative assessment. Assessment in Education, 4(3), 365-379. http://dx.doi.org/10.1080/0969594970040304

Hattie, J. (2009). Visible learning: A synthesis of over 800 meta-analyses relating to 
achievement. London, England: Routledge.

Heritage, M. (2007). Formative assessment: What do teachers need to know and do? Phi Delta Kappan, 89(2), 140. http://dx.doi.org/10.1177/003172170708900210

Herman, J., Osmundson, E., Dai, Y., Ringstaff, C., \& Timms, M. (2015). Investigating the dynamics of formative assessment: relationships between teacher knowledge, assessment practice and learning. Assessment in Education: Principles, Policy \& Practice, 22(3), 344-367. http://dx.doi.org/10.1080/0969594X.2015.1006521

Hojnoski, R. L., Gischlar, K. L., \& Missall, K. N. (2009). Improving child outcomes with data-based decision making: Collecting data. Young Exceptional Children, 12(3), 32-44. http://dx.doi.org/10.1177/1096250609333025

Hoover, N. R., \& Abrams, L. M. (2013). Teachers' instructional use of summative student assessment data. Applied Measurement in Education, 26(3), 219-231. http://dx.doi.org/10.1080/08957347.2013.793187

Horn, I. S., Kane, B. D., \& Wilson, J. (2015). Making sense of student performance data: Data use logics and mathematics teachers' learning opportunities. American Educational Research Journal, 52(2), 208-242. http://dx.doi.org/10.3102/0002831215573773

Italiano, F., \& Hine, G. (2014). Finding ways to effectively use year 12 achievement data to inform practice in secondary schools. Australian Journal of Teacher Education, 39(5), 99-116. http://dx.doi.org/10.14221/ajte.2014v39n5.8

Kinnucan-Welsch, K., Rosemary, C. A., \& Grogan, P. R. (2006). Accountability by design in literacy professional development. The Reading Teacher, 59(5), 426-435. http://dx.doi.org/10.1598/RT.59.5.2

LaFee, S. (2002). Data-driven districts. School Administrator, 59(11), 6-7, 9-10, 2, 14-15.

Lalli, J. S., Browder, D. M., Mace, F. C., \& Brown, D. K. (1993). Teacher use of descriptive analysis data to implement interventions to decrease students' problem behaviors. Journal of Applied Behavior Analysis, 26(2), 227-238. http://dx.doi.org/10.1901/jaba.1993.26-227

Lave, J., \& Wenger, E. (1991). Situated learning: Legitimate peripheral participation. New York: Cambridge University Press. http://dx.doi.org/10.1017/CBO9780511815355

Milanowski, A. (2004). The relationship between teacher performance evaluation scores and student achievement: Evidence from Cincinnati. Peabody Journal of Education, 79(4), 33-53. http://dx.doi.org/10.1207/s15327930pje7904_3

Mui So, W. W., \& Hoi Lee, T. T. (2011). Influence of teachers' perceptions of teaching and learning on the implementation of assessment for learning in inquiry study. Assessment in Education: Principles, Policy \& Practice, 18(4), 417-432. http://dx.doi.org/10.1080/0969594X.2011.577409

Parise, L. M., \& Spillane, J. P. (2010). Teacher learning and instructional change: how formal and on-the-job learning opportunities predict change in elementary school teachers' 
practice. The Elementary School Journal, 110(3), 323-346. http://dx.doi.org/10.1086/648981

Penuel, W. R., Fishman, B. J., Yamaguchi, R., \& Gallagher, L. P. (2007). What makes professional development effective? Strategies that foster curriculum implementation. American Educational Research Journal, 44(4), 921-958. http://dx.doi.org/10.3102/0002831207308221

Sato, M., Wei, R. C., \& Darling-Hammond, L. (2008). Improving teachers' assessment practices through professional development: the case of national board certification. American Educational Research Journal, 45(3), 669-700. http://dx.doi.org/10.3102/0002831208316955

Shapiro, E. S., Hilt-Panahon, A., Gischlar, K. L., Semeniak, K., Leichman, E., \& Bowles, S. (2011). An analysis of consistency between team decisions and reading assessment data within an RTI model. Remedial and Special Education, 33(6), 337-3347.

Shavelson, R. J., Young, D. B., Ayala, C. C., Brandon, P. R., Furtak, E. M., Ruiz-Primo, M. A. $\&$ Yin, Y. (2008). On the impact of curriculum-embedded formative assessment on learning: A collaboration between curriculum and assessment developers. Applied Measurement in Education, 21(4), 295-314. http://dx.doi.org/10.1080/08957340802347647

Shepard, L. A. (2000). The role of assessment in a learning culture. Educational Researcher, 29(7), 4-14. http://dx.doi.org/10.3102/0013189X029007004

Stiggins, R. (2005). From formative assessment to assessment for learning: A path to success in standards-based schools. The Phi Delta Kappan, 87(4), 324-328. http://dx.doi.org/10.1177/003172170508700414

Stiggins, R. J. (2002). Assessment crisis: The absence of assessment for learning. Phi Delta Kappan, 83(10), 758. http://dx.doi.org/10.1177/003172170208301010

Vygotsky, L. S. (1978). Mind in society: The development of higher psychological processes. Cambridge, MA: Harvard University Press.

Wayman, J. C. (2005). Involving teachers in data-driven decision making: Using computer data systems to support teacher inquiry and reflection. Education for Students Places At-Risk, 10(3), 295-308. http://dx.doi.org/10.1207/s15327671espr1003_5

Wiggins, G. P. (1998). Educative assessment: Designing assessments to inform and improve student. San Francisco, CA: Jossey-Bass.

Wiliam, D. (2007). Keep learning on track: Classroom assessment and the regulation of learning. In F.K. Lester (Ed.), Second Handbook of Research on Mathematics Teaching and Learning (Vol. 2, pp. 1053-1098). Charlotte: Information Age.

Young, V. M., \& Kim, D. H. (2010). Using assessments for instructional improvement: A literature review. Education Policy Analysis Archives, 18(19), 1-40. 
http://dx.doi.org/10.14507/epaa.v18n19.2010

\section{Copyright Disclaimer}

Copyright for this article is retained by the author(s), with first publication rights granted to the journal.

This is an open-access article distributed under the terms and conditions of the Creative Commons Attribution license (http://creativecommons.org/licenses/by/3.0/). 